\section{Padrão dietético e estado nutricional de operários de uma empresa metalúrgica do Rio de Janeiro, Brasil}

\author{
Dietary pattern and nutritional status \\ of metalworkers in Rio de Janeiro, Brazil
}

Maria Beatriz Trindade de Castro 1

Luiz Antonio dos Anjos 2,3

Paulo Maurício Lourenço 1

\author{
${ }^{1}$ Instituto de Medicina \\ Estado do Rio de Janeiro, \\ Rio de Janeiro, Brasil. \\ 2 Departamento de Nutrição \\ Social, Universidade Federal \\ Fluminense, Niterói, Brasil. \\ 3 Escola Nacional de Saúde \\ Pública, Fundação Oswaldo \\ Cruz, Rio de Janeiro, Brasil. \\ Correspondência \\ L. A. Anjos \\ Escola Nacional \\ de Saúde Pública, \\ Fundação Oswaldo Cruz. \\ Rua Leopoldo Bulhões 1480 \\ Rio de Janeiro, $R J$ \\ 21041-210, Brasil. \\ anjos@ensp.fiocruz.br
}

\section{Abstract}

Nutritional status, dietary and leisure-time physical activity patterns, and energy intake of 65 male metalworkers aged 19 to 58 years from Rio de Janeiro, Brazil, are described in the context of a surveillance build-up system. Mean body mass index was $25.0 \mathrm{~kg} / \mathrm{m}^{2}$ (44.6\% of the workers were overweight), and mean daily energy intake was 3,209.1 kcal, with a macronutrient distribution of $17.8 \%, 21.8 \%$, and $60.6 \%$ of protein, lipids, and carbohydrates, respectively. The most frequently eaten foods were rice, beans, bread, coffee, sugar, butter, juice, whole milk, soda, beef, and poultry. Vegetable, fruit, meat, and egg intakes were higher than the Food Pyramid Guide suggested portions. The results show a paradox for a surveillance system: (1) high prevalence of overweight, but dietary macronutrients within internationally recommended levels; (2) a well-balanced dietary pattern; and (3) some leisure-time physical activity in half of the workers.

Occupational Health; Nutritional Assessment; Diet; Nutritional Status; Anthropometry

\section{Introdução}

A transição nutricional, na qual grande parte da população mundial vive, caracteriza-se pela redução na prevalência de desnutrição energética protéica com aumento generalizado na prevalência de sobrepeso que está ocorrendo não só nos países desenvolvidos, como também em países em desenvolvimento ${ }^{1}$ e destacandose como um dos maiores problemas atuais de saúde pública no mundo.

Muito embora o sobrepeso seja decorrente de inúmeros fatores, o seu principal determinante é o desequilíbrio entre a ingestão e o gasto energético, fatores que são modulados pelas características sociais e de estilo de vida 2 . Muito da dificuldade de se estabelecer alguma associação entre esses determinantes ${ }^{3}$ deve-se, também, aos poucos dados de base populacional sobre a aferição do padrão dietético e a prática de atividade física, seja durante o lazer ou o trabalho.

No Brasil, os dados referentes ao estado nutricional da população baseiam-se, fundamentalmente, em inquéritos antropométricos nacionais e regionais realizados nas últimas três décadas. Dados sobre o nível de atividade física de lazer na população em geral são praticamente inexistentes 4 , e há, também, muito pouca informação sobre o padrão de consumo alimentar e sobre o gasto energético.

Poucos estudos vêm sendo realizados com a finalidade de promover a saúde e a qualidade 
de vida em grupos específicos. Segundo o Centers for Disease Control and Prevention (CDC) americano, os projetos educacionais e de promoção da saúde deveriam ser planejados em larga escala e atender a um amplo número de indivíduos, como grupos comunitários e de trabalhadores, estudantes, grupos étnicos isolados ou centros religiosos que não tenham acesso aos programas tradicionais de saúde 5 . A informação sobre o estado nutricional de um indivíduo ou de uma coletividade torna-se mais um elemento do diagnóstico, um subsídio para o planejamento de ações com a finalidade de promover a saúde.

A vigilância nutricional, vista como um dos componentes das ações básicas de assistência à saúde, cria a possibilidade de se promover a qualidade de vida de um grupo e reduzir a ocorrência de doenças e complicações evitáveis 6 . Grande parte dos estudos realizados mostra que o controle dos fatores dietéticos pode prevenir consideravelmente as mortes prematuras para a maioria dos adultos que não bebem e não fumam nos Estados Unidos da América 5, já que, quando se conhece o perfil de uma população, de um grupo ou de indivíduos, cria-se a possibilidade de elaborar estratégias direcionadas para atender as necessidades específicas e não apenas seguir modelos empregados em outros países ou em outras situações.

O presente estudo foi, então, desenvolvido numa empresa de prestação de serviço de refrigeração com o propósito de conhecer o perfil dietético e nutricional dos trabalhadores na perspectiva de subsidiar programas de vigilância em saúde do trabalhador.

\section{Material e métodos}

A presente investigação baseia-se num estudo transversal descritivo realizado em trabalhadores de uma empresa metalúrgica prestadora de serviços de refrigeração da cidade do Rio de Janeiro, Brasil. A empresa foi escolhida por conveniência, por conhecimento dos profissionais de saúde que autorizaram a realização das medições durante exame médico periódico de rotina. O objetivo do estudo, seus procedimentos e a participação voluntária foram devidamente explicados a todos os 137 metalúrgicos da empresa. Desse total, optou-se por estudar somente os 79 trabalhadores $(57,7 \%)$ que eram supervisores, mecânicos ou ajudantes de mecânico do sexo masculino, com idade entre 19 e 58 anos. Os 58 metalúrgicos que não participaram do estudo trabalhavam em equipes com menos de quatro funcionários ou eram técnicos, trabalhadores plantonistas, estavam de folga ou afastados por licença médica. As equipes menores não foram consideradas no planejamento do estudo pela diferença na composição da força de trabalho, tratando-se, na sua maioria, de equipes automatizadas. Dos 79 operários, 65 trabalhadores permaneceram nas análises após a exclusão de dados de 14 trabalhadores por possível sub e superestimativa no consumo alimentar. Posteriormente, cada participante recebeu o resultado da sua avaliação antropométrica e a indicação de um encaminhamento a um profissional da área de saúde quando pareceu necessário.

\section{Dados antropométricos}

O trabalho de campo, para coleta das variáveis antropométricas e dietéticas, foi realizado, no período de janeiro e fevereiro de 2000, por uma nutricionista previamente treinada. Foram usadas como variáveis antropométricas de interesse a massa corporal, a estatura, os perímetros da cintura e do quadril, obtidas seguindo padronização de Lohman et al.7. Durante a tomada das variáveis antropométricas, alguns critérios foram estipulados para padronizar a coleta de dados 7 . A massa corporal foi aferida uma vez em quilogramas ( $\mathrm{kg}$ ) usando balança eletrônica Secca (modelo 870), com capacidade para $130 \mathrm{~kg}$ e variação de $0,1 \mathrm{~kg}$. Para a medida, todos os trabalhadores ficaram sem sapatos, com os bolsos vazios e usando uniforme padrão adotado pela empresa. A estatura foi aferida uma vez em centímetros, com fita métrica inelástica de $150 \mathrm{~cm}$ de comprimento, afixada em parede plana, sem rodapé, a $50 \mathrm{~cm}$ do chão. Os indivíduos foram medidos descalços em posição ortostática, com os olhos no plano Frankfört, com as costas e a parte posterior dos joelhos encostados à parede. Um esquadro de madeira foi colocado na parte superior da cabeça, e a medida foi obtida com precisão de $0,1 \mathrm{~cm}$. Os perímetros corporais foram medidos uma vez com fita métrica inelástica e precisão de $0,1 \mathrm{~cm}$. O perímetro da cintura foi aferido com o operário em apnéia após uma inspiração, no ponto do menor perímetro na região abdominal. Os indivíduos encontravam-se em posição ereta, sem camisa, com o abdômen relaxado, braços estendidos ao longo do corpo e os pés juntos. O perímetro do quadril foi medido no 
ponto de maior perímetro passando pelas nádegas, com os indivíduos mantendo-se em posição ereta, braços ao lado do corpo e pés juntos.

A partir da aferição dessas medidas antropométricas, alguns índices foram obtidos: (1) o índice de massa corporal (IMC), calculado pela divisão da massa corporal em quilogramas pela estatura, em metros, ao quadrado e (2) a razão do perímetro cintura/quadril 8 .

As variáveis antropométricas empregadas para avaliar o estado nutricional dos operários foram analisadas de forma descritiva. Usou-se o valor de IMC $\geq 25,0 \mathrm{~kg} / \mathrm{m}^{2}$ para se caracterizar o sobrepeso ${ }^{9}$. O índice da razão do perímetro da cintura/quadril (RCQ) foi analisado segundo o ponto de corte adotado pelo CDC 8, que considera a razão $\leq 0,9$ como valor seguro para homens. Comparou-se o valor do perímetro da cintura (PC) com a classificação de risco sugerida pela Organização Mundial da Saúde (OMS) 9: risco para valores de $\mathrm{PC} \geq 94 \mathrm{~cm}$ e risco substancialmente aumentado para o $\mathrm{PC} \geq 102 \mathrm{~cm}$.

\section{Dados dietéticos}

Utilizou-se o questionário de freqüência de consumo alimentar semiquantitativo (QFCA) para a obtenção dos dados dietéticos 3 cujos resultados foram descritos de duas formas distintas: quantitativamente, através da ingestão energética total (IE) e da gramatura e da composição percentual dos macronutrientes; e qualitativamente, pela freqüência de consumo dos itens alimentares, por meio da distribuição dos grupos alimentares 10 e pela gramatura proporcional, descritas a seguir.

\section{- Ingestão energética (IE)}

Para calcular a IE, a quantidade de porções de cada alimento consumido pelo indivíduo era multiplicada pela porção média em gramas previamente utilizada por Sichieri 3 com base na publicação de Pinheiro 11 e, posteriormente, por uma constante, calculada para cada categoria de freqüência: nunca ou quase nunca $(0,036)$; uma a três vezes por mês $(0,071)$; uma vez na semana $(0,14)$; de duas a quatro vezes na semana $(0,43)$; de cinco a seis vezes na semana $(0,79)$; uma vez por dia $(1,0)$; de duas a três vezes por dia $(2,5)$; e mais de três vezes ao dia $(3,0)$. Após obter o valor total em gramas/dia de cada alimento, com o auxílio do Programa de Apoio à Nutrição (PAN) elaborado pela Universidade Federal de São Paulo 12, pôde-se calcular a gramatura dos macronutrientes: proteína, lipídio e carboidrato. Em seguida, foram calculados o valor energético total diário, a partir da gramatura obtida, e a distribuição percentual dos macronutrientes. Alguns alimentos presentes no QFCA que não constavam no PAN tiveram suas composições acrescentadas a partir dos dados presentes na Tabela de Composição Química de Alimentos 13 ou na Tabela para Avaliação de Consumo Alimentar em Medidas Caseiras 11. Foram adotados como pontos de corte para analisar a composição percentual das proteínas, dos carboidratos e dos lipídios da dieta os valores de 15, 60 e 30, respectivamente, baseados nos valores máximos preconizados pela OMS 2 .

\section{- Freqüência dos alimentos}

As freqüências dos alimentos ingeridos foram categorizadas através do seu consumo diário, semanal, mensal ou raro. Para categorizar o consumo dos alimentos no ano, foram geradas novas variáveis a partir das freqüências obtidas no QFCA. Todas as freqüências iguais ou superiores a seis foram transformadas em 1; as freqüências maiores e iguais a três e menores ou iguais a cinco foram codificadas em 2; as freqüências menores ou iguais a dois e maiores que um foram codificadas como 3; e, por último, as freqüências menores ou iguais a um foram transformadas em 4 , representando, respectivamente, um consumo diário, semanal, mensal e raro.

\section{- Grupos alimentares}

A análise qualitativa dos grupos alimentares foi realizada com base no Guia da Pirâmide Alimentar 10 e baseia-se em porções distribuídas proporcionalmente em oito grupos alimentares: pães, cereais, raízes e tubérculos; hortaliças; frutas; carnes; leite; leguminosas; óleos e gorduras; açúcares e doces.

A gramatura, de cada alimento consumido por cada operário, totalizada em um banco de dados, foi dividida pela gramatura da sua respectiva porção no Guia da Pirâmide Alimentar. Cada grupo alimentar foi calculado a partir da soma da porção de cada alimento relativo aos oito grupos alimentares. Alguns alimentos presentes no QFCA que não constavam na listagem dos grupos alimentares no Guia da Pirâmide Alimentar foram incluídos nas análises após serem devidamente separados em porções no PAN. A gramatura do alimento incluído foi calculada com base no valor energético respectivo ao seu grupo alimentar. Bebidas alcoólicas, café e mate não foram incluídos nessas análises. 


\section{- Gramatura proporcional}

A gramatura proporcional foi calculada a partir da divisão da quantidade de alimento consumido pela gramatura da sua respectiva porção e depois pela gramatura total do seu grupo alimentar correspondente.

\section{Critérios de exclusão}

Para não incluir, nas análises, dados dietéticos dos trabalhadores que possivelmente subestimaram ou superestimaram o seu consumo alimentar, foi calculada a razão entre a IE e a taxa metabólica basal (TMB), estimada pelas equações de predição da Food and Agriculture Organization/World Health Organization/United Nations University 14 , índice a partir do qual se pode estabelecer critérios para sub e superestimação da ingestão energética, atualmente chamado de critério de Goldberg ${ }^{15}$. Os valores da razão IE/TMB $<0,9$ e $>3,0$ foram utilizados na identificação de sub e superestimativa de IE, respectivamente, e foram desconsiderados nas análises quantitativas.

\section{Requerimento energético}

Para calcular o requerimento energético (RE) individualmente dos operários estudados, foram empregadas as equações de predição da TMB sugeridas para uso internacional, considerando o valor da massa corporal atual e o sexo dos trabalhadores 16. Posteriormente, optou-se por utilizar o valor de múltiplo da TMB de 2,1 proposto pela OMS 14 como uma estimativa aproximada do gasto energético médio diário correspondente às atividades ocupacionais pesadas.

\section{Atividade física de lazer}

Os operários responderam a questões referentes ao deslocamento para o trabalho e à realização de atividades físicas de lazer, seguindo questionário usado por Sichieri ${ }^{3}$. As análises estatísticas descritivas foram realizadas no programa Stata 6.0.

\section{Resultados}

Os 65 trabalhadores avaliados tinham idade média de 34,6 $\pm 11,43$ anos ( \pm desvio padrão) e massa corporal e estatura média de 74,1 \pm $14,88 \mathrm{~kg}$ e $172,1 \pm 6,62 \mathrm{~cm}$, respectivamente. O IMC médio encontrado foi de $25,0 \pm 4,66 \mathrm{~kg} / \mathrm{m}^{2}$, e o perímetro de cintura médio obtido, de $85,8 \pm$ $10,19 \mathrm{~cm}$ (Tabela 1). Entre os trabalhadores, 29 $(44,6 \%)$ apresentaram sobrepeso, 18 indivíduos $(27,7 \%)$ apresentaram RCQ $>0,9$, e $15(23,1 \%)$ operários estavam com ambas as medidas acima dos pontos de corte recomendados (Tabela 2). Treze metalúrgicos $(20,0 \%)$ tinham valores de perímetro da cintura maiores do que $94 \mathrm{~cm}$, e somente três $(4,6 \%)$ apresentaram perímetro da cintura superior a $102 \mathrm{~cm}$. Todos os trabalhadores com IMC $\geq 30 \mathrm{~kg} / \mathrm{m}^{2}$ apresentaram perímetro de cintura superior a $94 \mathrm{~cm}$.

\section{Dieta}

As análises do padrão de consumo alimentar quantitativo mostraram valor médio de IE de $3.209,1 \pm 889,73 \mathrm{kcal}$, composto de $60,6 \pm 7,29 \%$ de carboidratos, $21,8 \pm 5,23 \%$ de lipídios e 17,8 $\pm 3,55 \%$ de proteínas. A média da TMB predita foi de $1.772,5 \pm 201,62 \mathrm{kcal} / \mathrm{dia}$, representando um requerimento energético médio de 3.722,3 \pm

Média e desvio padrão das variáveis antropométricas e da idade de 65 operários de uma empresa metalúrgica do Rio de Janeiro, Brasil, 2000.

\begin{tabular}{|c|c|c|c|c|}
\hline Variáveis & Média & Desvio padrão & Mínimo & Máximo \\
\hline Idade (anos) & 34,60 & 11,43 & 19,00 & 58,00 \\
\hline Massa corporal $(\mathrm{kg})$ & 74,10 & 14,88 & 51,60 & 144,60 \\
\hline Estatura $(\mathrm{cm})$ & 172,10 & 6,62 & 155,40 & 187,00 \\
\hline Índice de massa corporal (kg/m²) & 25,00 & 4,66 & 18,70 & 48,90 \\
\hline \multicolumn{5}{|l|}{ Perímetros $(\mathrm{cm})$} \\
\hline Cintura & 85,80 & 10,19 & 68,00 & 128,50 \\
\hline Quadril & 98,20 & 8,20 & 83,00 & 135,60 \\
\hline Razão cintura/quadril & 0,87 & 0,05 & 0,79 & 0,99 \\
\hline
\end{tabular}


$423,40 \mathrm{kcal} / \mathrm{dia}$, o que significa que houve balanço energético (BE) médio negativo de 513,2 \pm $891,94 \mathrm{kcal} / \mathrm{dia}$.

No total, 47 trabalhadores $(72,3 \%)$ apresentaram BE negativo, e 18 (27,7\%), BE positivo. As análises da relação entre o BE com o IMC mostraram que, dos 29 trabalhadores com IMC $\geq$ $25 \mathrm{~kg} / \mathrm{m}^{2}, 23$ operários $(79,3 \%)$ apresentaram BE negativo, e, dos 36 trabalhadores com IMC $<25 \mathrm{~kg} / \mathrm{m}^{2}, 24(66,7 \%)$ apresentaram BE negativo (Tabela 3 )

1) Freqüência dos alimentos

Os alimentos mais consumidos no dia-adia dos trabalhadores foram, em ordem decrescente, arroz, feijão, pão, café, açúcar, manteiga, suco, leite integral, refrigerante e a carne vermelha sem osso. As frutas mais consumidas diariamente foram a banana e a laranja, enquanto o tomate e a alface foram as hortaliças mais consumidas. A qualidade dos alimentos consumidos em cada grupo ficou um pouco diferenciada quando se considerou a sua freqüência semanal. Nesse caso, o frango apresentou-se mais comumente consumido que a carne vermelha, e a laranja apareceu mais freqüentemente que a banana.

Tabela 2

Relação entre o índice de massa corporal e a razão cintura/quadril entre os 65 operários de uma empresa metalúrgica do Rio de Janeiro, Brasil, 2000.

\begin{tabular}{|c|c|c|c|c|c|c|}
\hline \multirow{3}{*}{$\begin{array}{l}\text { Índice de massa } \\
\text { corporal }\left(\mathrm{kg} / \mathrm{m}^{2}\right)\end{array}$} & \multirow[b]{3}{*}{$n$} & \multirow[b]{3}{*}{$\%$} & \multicolumn{4}{|c|}{ Razão cintura/quadril } \\
\hline & & & \multicolumn{2}{|c|}{$\leq 0,90$} & \multicolumn{2}{|c|}{$>0,90$} \\
\hline & & & $n$ & $\%$ & $\mathrm{n}$ & $\%$ \\
\hline$<25,0$ & 36 & 55,4 & 33 & 50,8 & 3 & 4,6 \\
\hline$\geq 25,0$ & 29 & 44,6 & 14 & 21,5 & 15 & 23,1 \\
\hline Total & 65 & 100,0 & 47 & 72,3 & 18 & 27,7 \\
\hline
\end{tabular}

Tabela 3

Relação entre o balanço energético e o índice de massa corporal do grupo de 65 operários de uma empresa metalúrgica do Rio de Janeiro, Brasil, 2000.

\begin{tabular}{|c|c|c|c|c|c|c|}
\hline \multirow{3}{*}{$\begin{array}{l}\text { Índice de massa } \\
\text { corporal }\left(\mathrm{kg} / \mathrm{m}^{2}\right)\end{array}$} & \multirow[b]{3}{*}{$\mathrm{n}$} & \multirow[b]{3}{*}{$\%$} & \multicolumn{4}{|c|}{ Balanço energético (\%) } \\
\hline & & & \multicolumn{2}{|c|}{ Negativo } & \multicolumn{2}{|c|}{ Positivo } \\
\hline & & & $\mathrm{n}$ & $\%$ & $n$ & $\%$ \\
\hline$<25,0$ & 36 & 55,4 & 24 & 66,7 & 12 & 33,3 \\
\hline$\geq 25,0$ & 29 & 44,6 & 23 & 79,3 & 6 & 20,7 \\
\hline Total & 65 & 100,0 & 47 & 72,3 & 18 & 27,7 \\
\hline
\end{tabular}

Os alimentos menos freqüentes na dieta dos operários foram o leite desnatado, o camarão, o milho e o peixe enlatado. No grupo das frutas e das hortaliças, os alimentos menos consumidos foram a goiaba, a chicória e a abobrinha, respectivamente. A cachaça e o mate foram as bebidas menos freqüentes.

2) Grupos alimentares

Os resultados qualitativos do padrão de consumo referentes aos grupos alimentares (Tabela 4) mostraram que os grupos das leguminosas, de carnes e ovos, frutas e hortaliças ultrapassaram as porções preconizadas pelo GPA. O consumo de laticínios e gorduras ficou abaixo do recomendado, enquanto o grupo dos cereais, pães, raízes e tubérculos e o grupo dos açúcares mantiveram-se dentro do intervalo proposto para homens com atividade intensa.

Dentre os grupos alimentares que ultrapassaram o número máximo de porções propostas pelo GPA, o grupo das leguminosas foi o que mais se excedeu. Seu consumo foi de 2,80 porções acima do recomendado. O grupo das frutas, assim como o grupo das carnes e ovos, permaneceu uma porção acima do máximo estabelecido. Se incluirmos o suco de fruta, o consumo das frutas passa a ser quase o dobro. $\mathrm{O}$ consumo de hortaliças ficou meia porção acima do limite superior.

O grupo dos açúcares apresentou-se no limite inferior recomendado e foi composto basicamente de açúcar. Quando o chocolate em barra e o chocolate em pó são incluídos nesse grupo, o número da porção sobe para 1,38, e, quando considera-se a ingestão de refrigerante, a porção ultrapassa o limite superior, ficando igual a 2,07.

3) Gramatura proporcional

As análises sobre o consumo percentual em gramas dos alimentos mostraram que, no grupo dos cereais, pães, raízes e tubérculos, os alimentos que mais contribuíram foram o arroz e o pão, seguidos do macarrão. O grupo das leguminosas foi representado praticamente pelo feijão. Dentre o grupo de carnes e ovos, as carnes que mais contribuíram em gramas foram a carne vermelha sem osso, o peixe, a rabada, o frango e o ovo.

Por meio desses resultados, pode-se perceber que, embora o frango seja mais freqüente, esse é consumido em menores porções que a carne de vaca sem osso (bife), o peixe e a carne vermelha com osso. No grupo das frutas, embora a laranja e a banana sejam mais constantes na alimentação dos operários, quando a manga é consumida, as suas porções são maiores. Já a alface, bastante comum no consumo dos traba- 
lhadores, é consumida em porções menores, enquanto o tomate apresenta-se freqüente, sendo consumido em grandes quantidades.

\section{Atividade física}

Entre os 65 operários metalúrgicos estudados, $34(52,0 \%)$ disseram realizar alguma atividade física de lazer, e 18 (27,7\%) trabalhadores relataram realizá-la três vezes ou mais no decorrer da semana. Entre os trabalhadores com idade inferior e igual ou superior a trinta anos, respectivamente, $8(28,6 \%)$ e $23(62,1 \%)$ disseram ser inativos.

Com relação à atividade física de lazer e ao sobrepeso, entre os 29 operários $(44,6 \%)$ com IMC $\geq 25 \mathrm{~kg} / \mathrm{m}^{2}, 17(58,6 \%)$ eram inativos, e, entre os 36 trabalhadores $(55,4 \%)$ com IMC < $25 \mathrm{~kg} / \mathrm{m}^{2}, 14(38,9 \%)$ não realizavam atividade física de lazer.

\section{Discussão}

Os dados antropométricos obtidos nesse trabalho indicaram alta freqüência de sobrepeso, inesperada para um grupo de trabalhadores de atividade laboral intensa. Entretanto, a prevalência de sobrepeso (IMC $\geq 25 \mathrm{~kg} / \mathrm{m}^{2}$ ) refletiu o quadro atual encontrado em pesquisas realizadas no Brasil 17,18. Segundo Castro 19, os dados obtidos na Pesquisa sobre Padrões de Vida (PPV) indicaram prevalência de sobrepeso e obesidade no sexo masculino da área urbana da região Sudeste do Brasil de 37,2\% e 8,0\%, respectivamente, valores bem próximos aos verificados entre os trabalhadores metalúrgicos.

Embora valores de IMC acima de $30 \mathrm{~kg} / \mathrm{m}^{2}$ sirvam como critério para definir obesidade em populações 20 , seu emprego deve ser cauteloso, pois esse índice, na verdade, não mede o excesso de massa gorda. Entretanto, motivos suficientes são apresentados pelo IMC para ser utilizado em pesquisas epidemiológicas como indicador do estado nutricional 21. Por maior que seja a possível superestimativa da prevalência de sobrepeso, um grupo de operários em que quase metade deles apresenta algum grau de excesso de peso já indicaria a necessidade de intervenção nutricional, quando os trabalhadores pudessem ser orientados individualmente.

Os valores médios da gramatura percentual dos macronutrientes apresentaram-se bem próximos aos valores propostos pela OMS 2 . O percentual de $21,8 \% \pm 5,23$ de lipídio nos metalúrgicos indica, segundo o Dietary Guidelines Advisory Commitee 22, uma dieta com baixo
Tabela 4

Relação do número de porções propostas pelo Guia da Pirâmide Alimentar e o número de porções encontradas entre os 65 operários de uma empresa metalúrgica do Rio de Janeiro, Brasil, 2000.

\begin{tabular}{lcc}
\hline Grupos alimentares & $\begin{array}{c}\text { Número de porções } \\
\text { médias encontradas }\end{array}$ & $\begin{array}{c}\text { Intervalo de porções } \\
\text { recomendadas }\end{array}$ \\
\hline Cereais, tubérculos, raízes e pães & 8,97 & $5-9$ \\
Leguminosas & 3,83 & 1 \\
Hortaliças & 5,45 & $4-5$ \\
Leite e derivados & 1,79 & 3 \\
Carnes & 3,18 & $1-2$ \\
Gorduras & 0,37 & $1-2$ \\
Frutas & 6,26 & $3-5$ \\
Frutas e suco & 9,40 & $3-5$ \\
Açúcar & 1,02 & $1-2$ \\
Açúcar e chocolate & 1,38 & $1-2$ \\
Açúcar, chocolate e refrigerante & 2,07 & $1-2$ \\
\hline
\end{tabular}

teor de gordura. Todavia, esse percentual baseia-se em uma ingestão energética de 3.209,1kcal, o que representa consumo diário de 80,1g de gordura, que não foi qualitativamente discriminada quanto a sua saturação. Pode ser que a gordura saturada ingerida tenha sido a níveis superiores ao recomendado de 8,0 a $10,0 \%$ do total de energia 23 .

Aproximadamente, dois terços dos trabalhadores metalúrgicos apresentaram BE negativo. No grupo de trabalhadores que tinham IMC $<25 \mathrm{~kg} / \mathrm{m}^{2}, 33,3 \%$ apresentaram BE positivo. A baixa prevalência de indivíduos com IMC $\geq 25 \mathrm{~kg} / \mathrm{m}^{2}$ e com BE positivo $(20,7 \%)$ parece corroborar o fato de que indivíduos com excesso de peso tendem a subestimar o consumo energético 24 .

$\mathrm{O}$ aparente grande número de $\mathrm{BE}$ negativo pode ser decorrente da superestimativa da TMB predita para o cálculo do requerimento energético ou do emprego da atividade laboral de nível intenso como múltiplo da TMB para cálculo da recomendação energética. Quando a razão IE/TMB foi calculada, os valores obtidos apresentaram-se maiores que os encontrados na literatura investigada 15,25,26 apesar do BE negativo para a maioria dos trabalhadores. Nesse caso, a TMB, por si só, não explicaria a razão IE/TMB de 1,82 $\pm 0,51$ entre os 65 operários. Nos estudos realizados por Briefel et al. 25,26 com os dados da população americana avaliados no National Health and Examination Survey III ( $\mathrm{n}=14.801)$, foram encontrados os seguintes valores da razão IE/TMB: 1,47 em homens adultos; 1,28 em homens com sobre- 
peso; 0,71 em homens que subestimam o consumo e 1,64 em homens que reportam acuradamente o consumo. O BE médio negativo em um grupo de trabalhadores no qual quase $50,0 \%$ deles apresentaram algum grau de sobrepeso reafirma a necessidade de se considerar individualmente o nível de intensidade laboral na caracterização do trabalho 27 e a necessidade de se reverem as equações de predição da TMB 28 , visto que essas podem vir a superestimar o RE, por considerarem, no seu cálculo, a massa corporal dos indivíduos independente do seu IMC ou da sua composição corporal. Além disso, talvez seja necessário rever os valores do nível de atividade física (NAF) a serem usados em populações de países em desenvolvimento 29 .

As análises do padrão de consumo alimentar qualitativo não indicaram padrão exagerado de consumo de produtos de alta densidade energética. Os alimentos mais consumidos diariamente parecem caracterizar os hábitos alimentares da população brasileira 17,30. Segundo Maluf 31, na última década, houve um aumento expressivo no consumo de carnes, vermelhas e de aves, e uma perda parcial do consumo de arroz, nas camadas com renda entre dois e cinco salários mínimos, para o aumento do macarrão, devido ao seu barateamento. No decorrer da semana, 50,0 a 60,0\% dos trabalhadores alimentavam-se de frango, bife, macarrão, laranja, ovo, queijo, tomate e alface. No geral, os trabalhadores apresentaram uma refeição bastante variada, também percebida nas análises dos grupos alimentares. Nela, os trabalhadores apresentaram padrão dietético bem próximo ao proposto pelo Guia da Pirâmide Alimentar 10. Os alimentos que ultrapassaram as porções propostas foram frutas, hortaliças, leguminosas e carnes. Castro 19 encontrou associação positiva entre dieta variada e IMC na PPV, sugerindo que, muito embora a restrição no consumo de lipídios seja recomendada, deve-se dar ênfase na redução do valor energético total, visto que o que estaria proporcionando o excesso de peso seria o consumo energético total.

Foi observado, entre os operários, maior consumo de refrigerante e carne do que aparece relatado em artigos científicos nacionais. Essa literatura baseia-se em análises de tendências temporais a partir de dados obtidos nas Pesquisas de Orçamento Familiar 32. Contudo, os operários apresentaram um alto consumo de leguminosas e de frutas.

O consumo de bebidas alcoólicas pareceu ser muito discreto ou ter sido relatado de forma distorcida. Embora o hábito de beber com os amigos após o expediente seja uma prática social muito comum, o fato dos dados dietéticos terem sido coletados no ambiente de trabalho pode ter favorecido a sua subestimativa. As bebidas destiladas ficaram entre os alimentos consumidos com menor freqüência, e a cerveja apresentou consumo médio de dois copos por pessoa e com freqüência de uma a três vezes ao mês, bem abaixo do esperado. Num estudo realizado por Barros \& Nahas 33 com trabalhadores da indústria de Santa Catarina, observou-se consumo médio de duas doses de bebida alcoólica por semana, entretanto, $48,0 \%$ dos trabalhadores relataram ter ingerido, no último mês, mais de cinco doses, em uma mesma ocasião.

As análises da gramatura percentual da porção dos grupos alimentares indicaram que determinados alimentos mais freqüentes na dieta podem estar sendo consumidos em porções menores que alimentos aparentemente mais raros, mas que, quando consumidos, são ingeridos em porções maiores, ou que o tamanho fixo das porções utilizadas para o cálculo do questionário estaria ocasionando estas diferenças. Por exemplo: o peixe consumido pelo menos uma vez por semana por $55,0 \%$ dos trabalhadores e o frango por $88,0 \%$ dos operários. No entanto, o tamanho do peixe representa, em média, $14,8 \%$ da porção do grupo das carnes e ovos, e o frango representa $11,4 \%$ da gramatura da porção. O efeito de alimentos de alta densidade energética, como bebidas alcoólicas, frituras e doces concentrados consumidos raramente em porções grandes, ou ainda, o efeito desses alimentos, consumidos em pequenas frações, mas que, se categorizados sob um mesmo grupo, deixariam de ser raros nas práticas alimentares e poderiam influenciar os resultados.

A atividade física de lazer pareceu estar presente no cotidiano de $50,0 \%$ dos trabalhadores metalúrgicos, prevalência, esta, superior aos poucos estudos existentes sobre atividade física na população brasileira e que chama atenção por ser em um grupo de trabalhadores com jornada de trabalho em torno de nove horas por dia e com demanda de esforço físico alto. Segundo estudo realizado no Município do Rio de Janeiro por Gomes et al. 34 , apenas $18,4 \%$ dos homens disseram praticar alguma atividade física de lazer ou esporte regularmente, e $3,6 \%$ tinham ocupação considerada pesada. A faixa etária mais ativa foi a mais jovem, e a faixa etária com idade maior ou igual a trinta anos foi a que mais relatou realizar outra atividade ocupacional fora do expediente. O esporte mais praticado foi o futebol, esporte mais popular do Brasil. 
Em suma, a realização desse estudo exploratório vem confirmar a necessidade da monitorização nutricional desses trabalhadores metalúrgicos, não somente pela alta freqüência de sobrepeso, como também pelo balanço energético médio negativo encontrado, o que sugere uma inadequação do padrão dietético aos requerimentos dos trabalhadores, principalmente entre os operários com sobrepeso. Tal- vez programas educacionais multidisciplinares, com nutricionistas, educadores físicos e médicos entre outros profissionais da saúde, pudessem orientar os trabalhadores na melhoria da qualidade de vida e reforçar hábitos saudáveis que já parecem existir: alto consumo de frutas e de legumes e prática de atividade física de lazer rotineira.

\section{Resumo}

Descrevem-se o estado nutricional, o padrão de consumo alimentar, a ingestão energética (IE) e a freqüência da atividade física de lazer de 65 operários (19 a 58 anos de idade) do sexo masculino na perspectiva de construção de um sistema de vigilância (SISVAN) numa empresa de metalurgia do Rio de Janeiro, Brasil. $O$ IMC médio foi de $25,0 \mathrm{~kg} / \mathrm{m}^{2}$ (44,6\% tinham sobrepesoSP), a IE, de 3.209,1 kcal/dia com 17,8; 21,8 e 60,6\% de proteínas, lipídios e glicídios, respectivamente. Os alimentos mais freqüentemente consumidos foram arroz, feijão, pão, café, açúcar, manteiga, suco, leite, refrigerante, bife e frango. O consumo de leguminosas, hortaliças, frutas, carnes e ovos ultrapassou o recomendado. Dos trabalhadores com SP, 79,0\% apresentaram balanço energético (BE) negativo. Os resultados mostraram um paradoxo a ser enfrentado pelo SISVAN: alta prevalência de SP, mas com BE negativo e com dieta com padrão qualitativo bem variado; $e$, ainda, prática de alguma atividade física de lazer por metade dos trabalhadores. Pode ser que esse aparente paradoxo seja causado por superestimativa dos requerimentos energéticos ou subestimativa da ingestão, fatores que não podem ser determinados na presente análise.

Saúde do Trabalhador; Avaliação Nutricional; Dieta; Estado Nutricional; Antropometria

\section{Colaboradores}

M. B. T. Castro e P. M. Lourenço contribuíram no planejamento da pesquisa e na coleta de dados antropométricos e dietéticos. Todos os autores participaram das análises, discussões sobre os resultados e da preparação da versão final do texto.

\section{Referências}

1. Monteiro CA, Mondini L, Souza AL, Popkin BM. Da desnutrição para a obesidade: a transição nutricional no Brasil. In: Monteiro CA, organizador Velhos e novos males da saúde do país. São Paulo: Editora Hucitec/Núcleo de Pesquisas Epidemiológicas em Nutrição e Saúde, Universidade de São Paulo; 1995. p. 247-55.

2. World Health Organization. Dieta, nutrición y prevención de enfermedades crónicas: Informe de un grupo de estudio de la OMS. Geneva: Food and Agriculture Organization/World Health Organization; 1990. (Série de Informes Técnicos 797).

3. Sichieri R. Epidemiologia da obesidade. Rio de Janeiro: EdUERJ; 1998.

4. Anjos LA. Prevalência da inatividade física no Brasil. In: Anais do 2o Congresso Brasileiro de Atividade Física \& Saúde; 1999 Nov 24-26; Florianópolis, Santa Catarina. Florianópolis: Centro de Desportos, Universidade Federal de Santa Catarina; 1999. p. 58-63.

5. National Center For Health Statistics. Healthy people 2000 review 1995-1996. Hyattsville: Public Health Services; 1996.

6. Sistema de Vigilância Alimentar e Nutricional. O sistema de vigilância alimentar e nutricional na rede de saúde: manual para implantação. Rio de Janeiro: Escola Nacional de Saúde Pública, Fundação Oswaldo Cruz; 1993.

7. Lohman TG, Roche AF, Martorell R. Anthropometric standardization reference manual. Champaign: Human Kinetics Books; 1988.

8. Centers for Disease Control and Prevention. Obesity and overweight, basics about overweight and obesity: defining the terms. http://www.cdc.gov/ nccdphp/dnpa/obesity/basic.html (acessado em 15/Jan/2002) 
9. World Health Organization. The use and interpretation of anthropometry: report of a WHO expert committee. Geneva: World Health Organization; 1995. (Technical Report Series 854).

10. Philippi ST, Latterza AR, Cruz ATR, Ribeiro LC. Pirâmide alimentar adaptada: guia para escolha dos alimentos. Rev Nutr 1999; 12:65-80.

11. Pinheiro ABV. Tabela para avaliação de consumo alimentar em medidas caseiras. 4a Ed. Rio de Janeiro: Atheneu; 2000.

12. Universidade Federal de São Paulo. Programa de apoio à nutrição. São Paulo: Escola Paulista de Medicina; Universidade Federal de São Paulo; 1995.

13. Franco G. Tabela de composição química dos alimentos. 9a Ed. Rio de Janeiro: Atheneu; 1992.

14. Food and Agriculture Organization/World Health Organization/United Nations University. Energy and protein requirements. Geneva: World Health Organization; 1985. (Technical Report Series 724).

15. Goldberg GR, Black AE, Jebb SA, Cole TJ, Murgatroyd PR, Coward WA, et al. Critical evaluation of energy intake data using fundamental principles of energy physiology: 1 . Derivation of cut-off limits to identify under-recording. Eur J Clin Nutr 1991; 45:569-81.

16. Vasconcellos MTL, Anjos LA. Taxa de adequação (ingestão/requerimento) de energia como indicador do estado nutricional das famílias: uma análise crítica dos métodos aplicados em pesquisas de consumo de alimentos. Cad Saúde Pública 2001; 17:581-93.

17. Sichieri R, Castro JFG, Moura AS. Fatores associados ao padrão de consumo alimentar da população brasileira. Cad Saúde Pública 2003; 19 Suppl $1: S 46-S 53$.

18. Ell E, Camacho LAB, Chor D. Perfil antropométrico de funcionários de banco estatal no Estado do Rio de Janeiro/Brasil: I - índice de massa corporal e fatores sócio-demográficos. Cad Saúde Pública 1999; 15:113-21.

19. Castro JFG. Padrões de consumo alimentar e índice de massa corporal nas regiões nordeste e sudeste do Brasil [Dissertação de Mestrado]. Rio de Janeiro: Instituto de Medicina Social, Universidade do Estado do Rio de Janeiro; 2001.

20. World Health Organization. Obesity: preventing and managing the global epidemic. Geneva: World Health Organization; 2000. (Technical Report Series 894).

21. Anjos LA. Índice de massa corporal (massa corporal.estatura-2) como indicador do estado nutricional de adultos: revisão da literatura. Rev Saúde Pública 1992; 26:431-6.

22. Dietary Guidelines Advisory Committee. Report of the Dietary Guidelines Advisory Committee on the dietary guidelines for americans, 2000. Washington DC: Department of Agriculture; 2000.
23. National Cholesterol Education Program. Second report of the expert panel on detection, evaluation, and treatment of high blood cholesterol in adults (adult treatment panel II). Circulation 1994; 89:1333-445.

24. Heitmann BL, Lissner L. Dietary underreporting by obese individuals-is it specific or non specific? Br Med J 1995; 311:986-9.

25. Briefel RR, McDowell MA, Alaimo K, Caughman CR, Bischof AL, Carroll MD, et al. Total energy intake of the US population: the third National Health and Nutrition Examination Survey, 19881991. Am J Clin Nutr 1995; 62 Suppl:1072S-80S.

26. Briefel RR, Sempos CT, McDowell MA, Chien S, Alaimo K. Dietary methods research in the third National Health and Nutrition Examination Survey: Underreporting of energy intake. Am J Clin Nutr 1997; 65 Suppl:1203S-9S

27. Anjos LA, Ferreira JA. A avaliação da carga fisiológica de trabalho na legislação brasileira deve ser revista! O caso da coleta de lixo domiciliar no Rio de Janeiro. Cad Saúde Pública 2000; 16:78590.

28. Wahrlich V, Anjos LA. Aspectos históricos e metodológicos da medição e estimativa da taxa metabólica basal: uma revisão da literatura. Cad Saúde Pública 2001; 17:801-17.

29. Vasconcellos MTL, Anjos LA. A simplified method for assessing physical activity level values for a country or study population. Eur J Clin Nutr 2003; 57:1025-33.

30. Sichieri R. Dietary patterns and their associations with obesity in the Brazilian city of Rio de Janeiro. Obes Res 2002; 10:42-9.

31. Maluf R. Consumo de alimentos no Brasil: traços gerais e ações públicas locais de segurança alimentar. Polis Paper no 6. http://www.polis.org. $\mathrm{br} /$ publicacoes/papers/20006.html (acessado em $15 / \mathrm{Jan} / 2002$ ).

32. Monteiro CA, Mondini L, Costa RBL. Mudanças na composição e adequação nutricional da dieta familiar nas áreas metropolitanas do Brasil. Rev Saúde Pública 2000; 34:251-8.

33. Barros MVG, Nahas MV. Comportamentos de risco, auto-avaliação do nível de saúde e percepcão de estresse em trabalhadores da indústria. Rev Saúde Pública 2001; 35:554-63.

34. Gomes VB, Siqueira KS, Sichieri R. Atividade física em uma amostra probabilística da população do Município do Rio de Janeiro. Cad Saúde Pública $2001 ; 17: 969-76$.

Apresentado em 16/Jan/2003

Versão final reapresentada em 06/Out/2003 Aprovado em 13/Out/2003 